\title{
CRIANZA DEL GRILLO (ACHETA DOMESTICUS) COMO FUENTE ALTERNATIVA DE PROTEÍNAS PARA EL CONSUMO HUMANO
}

\author{
Luis Apolo-Arévalo' y José lannacone
}

\section{RESUMEN}

El presente trabajo sobre crianza del grillo Acheta domesticus como fuente alternativa de proteínas para el consumo humano, tiene como objetivo realizar una revisión bibliográfica de los estudios en relación a su aprovechamiento masivo y eficiente de su biomasa para combatir los retos actuales de la seguridad alimentaria en comparación con las fuentes de origen animal convencionales. Se analizan las posibilidades que ofrece la producción de proteínas de $A$. domesticus para el consumo humano. También se presentan experiencias en el mantenimiento de reproducción de grillos, que incluye las condiciones y cuidados del grillo. Se evalúa la información publicada reciente en relación al uso, valor proteico y ventajas del consumo humano de $A$. domesticus.

Palabras ClaVE: Acheta domesticus, crianza, entomofagia, fuente alternativa de proteína, grillo, seguridad alimentaria.

\section{ABSTRACT}

This work on breeding of house cricket Acheta domesticus as an alternative source of protein for human consumption is to perform a literature review of studies regarding its massive and efficient biomass use to combat today's challenges of food security compared with conventional sources of animal origin. The potential of producing proteins of $A$. domesticus for human consumption are analyzed. It also presents experiences in maintaining reproduction of crickets, including the conditions and care of cricket. Recent published information regarding the use, protein value and advantages human consumption of $A$. domesticus is evaluated.

KEYWORDS: Acheta domesticus, alternative source of protein, breeding, cricket, entomophagy, food security. 


\section{Introducción}

E

I crecimiento poblacional ha aumentado la demanda de alimentos a escala mundial, especialmente las fuentes de proteínas de origen animal para lograr una seguridad alimentaria. La producción tradicional de harina de pescado, soja y cereales, debe intensificarse aún más en términos de eficiencia de recursos y ampliarse mediante el uso de fuentes alternativas (Halloran \& Vantomme, 2013).

En el año 2030 tendremos que alimentar a más de 9.000 mill de personas, miles de mill de animales que se crían anualmente con fines alimentarios, recreativos y como mascotas. Una de las muchas vías para abordar la seguridad alimentaria es a través de la cría de insectos (Arango et al., 2004; Gohar, 2012; Halloran \& Vantomme, 2013; Raubenheimer \& Rothman, 2013). El uso de insectos a gran escala como ingrediente en la composición de piensos es técnicamente viable, y en diversas partes del mundo existen empresas consolidadas que están a la vanguardia (Halloran \& Vantomme, 2013).

Los insectos están en todas partes, se reproducen rápidamente, poseen tasas elevadas de crecimiento y conversión de piensos, y un reducido impacto ambiental durante su ciclo de vida. Pueden criarse aprovechando diversos flujos de residuos de alimentos (Steinfeld et al., 2006; Quirce et al., 2013).

La microganadería entomológica usa el método zootécnico para la cría intensiva, sin afectar el ambiente, debido a que son cultivados en cautiverio bajo condiciones controladas (FAO, 2014). Pocas son las especies criadas a través de sistemas de "mini-ganaderías", como el gusano de la seda Bombyx mori (Linnaeus, 1758), las abejas melíferas Apis mellifera (Linnaeus, 1758) y los escarabajos del género Rhynchophorus, que probablemente estos últimos son los insectos no-domesticados más ampliamente cultivados en Asia, África y Latinoamérica (Defoliart, 1995; Pérez \& lannacone, 2006; Pérez et al., 2010; Sancho et al., 2015).

El valor nutritivo de los insectos es elevado, y su componente más importante son las proteínas que, en general, forman la mayor parte de su cuerpo y que se pueden calificar como de buena calidad (Raubenheimer \& Rothman, 2013). Los insectos en general contienen ácidos grasos, albergan vitaminas del grupo B, sales minerales, algunos son muy ricos en calcio, y son una fuente importante de magnesio (Hidalgo, 2005; Ramos-Elorduy et al., 2012; Ganguly et al., 2013). Los insectos aportan no sólo una gran cantidad de proteínas, sino que incluso pueden llegar a superar la calidad de las que proporcionan el pescado, el pollo y cualquier otra fuente proteínica, presentando un balance en la composición de aminoácidos (Hidalgo, 2005; Belluco et al., 2013). Son un recurso natural renovable que ha sido aprovechado desde la antigüedad con fines alimenticios y medicinales (Pijoan, 2001; Ramos-Elorduy \& Viejo, 2007; Quintero et al., 2012; Ramos-Elorduy et al., 2012; Navarro, 2013; Bidau, 2014).

La entomofagia constituye una alternativa alimenticia prometedora para el hombre, como lo comprueban diferentes investigaciones sobre insectos comestibles referentes 
a aspectos biogeográficos, a su biodiversidad en el mundo, a su sustentabilidad, a su importancia en la alimentación de los núcleos rurales, a su valor nutritivo habiéndose demostrado que son una buena fuente de proteínas, aunada a su calidad proteínica y a que son altamente digestibles (Ramos-Elorduy \& Pino, 2001; Escobar, 2013; Halloran \& Vantomme, 2013; Quirce et al., 2013; Raubenheimer \& Rothman, 2013; Caparros-Megido et al., 2014; Okore et al., 2014).

Se han registrado varios insectos comestibles, entre los más importantes están los órdenes Coleoptera, Hymenoptera, Orthoptera, y Lepidoptera (Neto \& Ramos-Elorduy, 2006; Echávarri, 2013; Ganguly et al., 2013; Chakravorty et al., 2014; Okore et al., 2014).

En el Perú, la crianza y consumo masiva del grillo común Acheta domesticus (Linnaeus, 1758), es una alternativa para alimento de ganado y otros animales de granja, como para consumo humano, aprovechando su alto valor nutricional, bajo costo de producción y menor impacto al ambiente (Nakagaki \& Defoliart, 1991; Ryder \& Siva-Jothy, 2001). En la actualidad a nivel mundial se cultiva comercialmente como una opción viable para la alimentación del ser humano, especies insectívoras y como cebo para la pesca deportiva (Garibay, 2007; FIA, 2013; Mellado, 2013; Natura, 2013; Raubenheimer \& Rothman, 2013; DPS, 2014; Halloran et al., 2014).

El objetivo del presente trabajo fue sistematizar la información sobre la crianza del grillo (A. domesticus), como fuente alternativa de proteínas para el consumo humano.

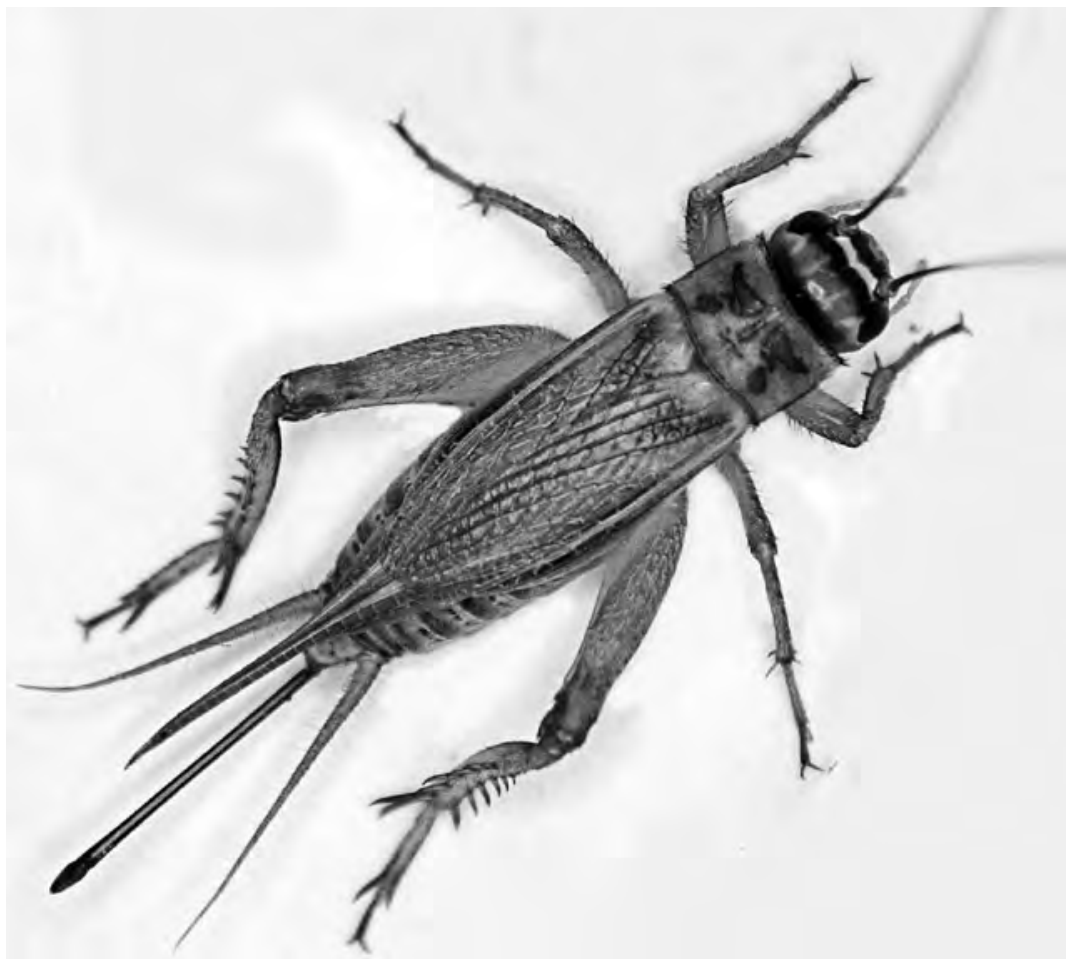

Figura 1. Hembra Adulta de Acheta domesticus. 


\section{Materiales y métodos}

Con el objetivo de evaluar la crianza del grillo (A. domesticus) (Fig. 1) como fuente alternativa de proteínas para el consumo humano, se realizó una búsqueda exhaustiva en Google académico, utilizando las palabras en español y equivalentes en inglés: "Acheta domesticus", "crianza de grillos", "biología de Acheta domesticus", "biología del grillo", "entomofagia", "proteínas en insectos", "alimentación a base de insectos", "alternativa de proteínas", "entomofagia en Perú", "composición química de insectos", "zoocriaderos de insectos" $y$ "zootecnia del grillo". También se obtuvo información de experiencias de criadores empíricos que destinan este recurso como alimento vivo para mascotas, especies comercializadas o de entretenimiento. Finalmente se realizó una revisión bibliográfica de páginas electrónicas de experiencias obtenidas de criadores de $A$. domesticus en función a la producción como alimento vivo, pienso y consumo humano. Se revisaron estudios de la biología de $A$. domesticus, y se muestran algunos prototipos piloto que corroboran los protocolos básicos para la crianza del grillo.

\section{Resultados y discusión}

Mantenimiento en cautividad y reproducción. Garibay (2007) explica el método zootécnico para la cría intensiva del grillo $A$. domesticus y considera los siguientes componentes.

Locación para la crianza del grillo. La locación es el lugar establecido para la crianza del grillo (Parajulee et al., 1993). Debe tener los siguientes servicios básicos como agua corriente, energía eléctrica y drenaje. Otros servicios útiles son teléfono, computadora personal e internet. Debe tenerse siempre en reserva: jaulas, agua purificada, alimento, hojas de control, etc.

\section{Control de la temperatura.}

El rango de temperaturas que debe haber dentro de las jaulas para grillos es entre un mínimo de veinte centígrados $\left(20^{\circ} \mathrm{C}\right)$, y un máximo treintaicinco centígrados $\left(35^{\circ} \mathrm{C}\right)$. Las jaulas para grillos dependen de generadores de temperatura ambientales puestos en lugares estratégicos dentro de la locación (Erens et al., 2012).

Los generadores de temperatura ambientales para grillos se clasifican en dos clases: (1) Generadores de calor para grillos: que sirven para elevar la temperatura dentro de las jaulas cuando la temperatura ambiente baja más del límite en el rango recomendado. El generador de calor más usado por los criadores de grillos es el calentador ambiental eléctrico; (2) Generadores de frío para grillos que sirven para bajar la temperatura dentro de las jaulas cuando la temperatura ambiente sube más del límite en el rango recomendado. El generador de frío más usado por los criadores de grillos es el enfriador ambiental 
eléctrico. Los grillos dentro de sus jaulas nunca deben ser expuestos a los rayos directos del sol, al frío directo, y la humedad, porque pueden ocasionar la muerte masiva de grillos.

\section{Jaulas para grillos.}

Las jaulas para grillos deber ser fáciles de manejar y de limpiar por el criador. Cada una de las jaulas para grillos debe estar marcada con la letra, el número de la fila y el lugar dentro de la locación para identificar un lote particular de grillos. La razón de hacer esto es porque los grillos no pueden ser marcados individualmente para identificarlos.

Las siguientes especificaciones están considerando una jaula que tiene incluida una cantidad suficiente de escondites para los grillos, los cuales aumentan la capacidad de cada jaula para contener más grillos (Fig. 2). La cantidad de grillos adultos que puede contener cada jaula depende de la capacidad en litros de cada jaula (Mazurkiewicz et al., 2013; Porter, 2015).

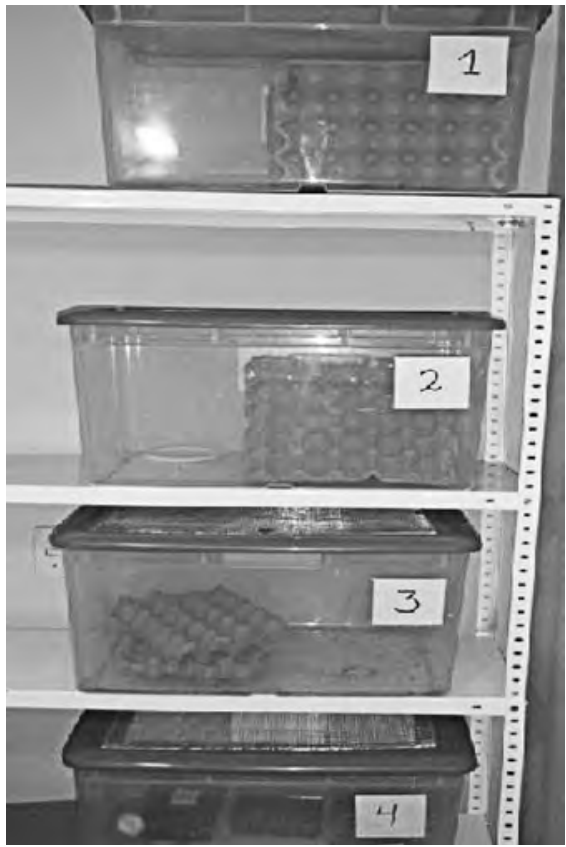

Figura 2. Jaulas de grillos (Acheta domesticus) rotuladas en el micro-ensayo piloto.

Una jaula de sesentaicinco litros de capacidad puede contener un máximo de dos mil grillos adultos. Una jaula de noventaicinco litros de capacidad puede contener un máximo de tres mil grillos adultos. Para grillos recién nacidos y para las primeras etapas ninfales, las jaulas necesitan ser más pequeñas que las usadas para grillos adultos, es decir, desde ocho, hasta quince litros de capacidad (Porter, 2015). Estas jaulas pequeñas también tienen la función de ser incubadoras para los huevos fertilizados de los grillos. 
Las jaulas para grillos pueden tener estructuras fabricadas con varios tipos de materiales como cartón, plástico, madera, vidrio, etc. (Mazurkiewicz et al., 2013). Para la estructura de una jaula para grillos, se necesita una caja de plástico grande, nueva y limpia. Las jaulas para grillos deben tener ventilación y debe estar en el techo de la jaula, y/o sus paredes. El mejor material para ser usado es una malla metálica de aluminio, con aberturas cuadradas para grillos recién nacidos y primeras etapas ninfales.

La malla metálica es fijada a la estructura de la jaula para grillos con silicón especial para sellar los paneles de vidrio de los acuarios. Otro tipo de silicón es tóxico para los grillos.

La cinta adhesiva lisa, es muy usada por los criadores para evitar escapes de grillos, y debe tener desde cinco $\mathrm{cm}$ hasta diez $\mathrm{cm}$ de ancho. La barrera de cinta adhesiva lisa debe ser adherida de forma horizontal sobre todos los bordes interiores de la jaula para grillos, y es recomendable aplicar dos líneas juntas, una al lado de la otra (Fig. 3).
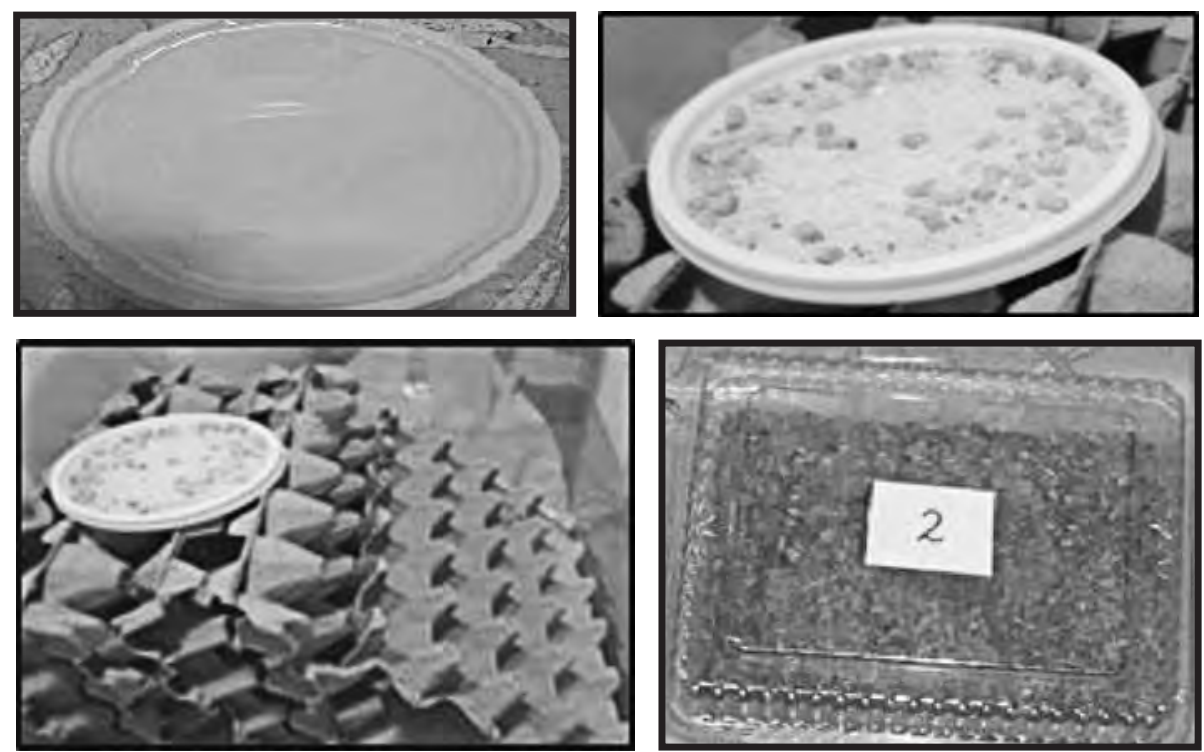

Figura 3. Bebedero, comedero, escondites y nidos para grillos (Acheta domesticus).

Los bebederos, y los comederos para grillos deben ser de baja altura, así los grillos pueden trepar fácilmente sobre estos, y también deben ser amplios para que una gran cantidad de grillos puedan beber, y comer a un mismo tiempo. Deben tener forma de una pequeña bandeja de poca profundidad, y con fondo plano. Pueden servir las tapas de plástico de algunos contenedores para comida.

Los escondites necesitan quedar por debajo de un tercio de la altura total de la jaula para grillos para evitar el escape de los grillos. El cartón para huevo es el material más usado por los criadores como escondites para grillos (Fig. 3). Los cartones para huevos deben ser puestos verticalmente para permitir la circulación del aire caliente para permitir que los residuos de los grillos (es decir: grillos muertos, pieles mudadas, heces, los residuos de 
los nutrientes) caigan sobre el fondo de la jaula. Los cartones para huevo deben colocarse juntos, uno al lado del otro, con todas las crestas y valles unas contra las otras, exactamente en la forma contraria en la cual estos se almacenan juntos (Porter, 2015).

La limpieza de cada jaula para grillos idealmente debe ser hecha cada tres o cuatro días como máximo. En cada sesión de limpieza de las jaulas para grillos deben quitarse: grillos muertos, pieles mudadas, heces, los residuos de los nutrientes, y si la estructura de la jaula está fabricada con cartón y está muy sucia, entonces también puede ser eliminada.

Las jaula-bebederos-comederos-nidos para grillos y otros utensilios deben ser lavados con jabón y detergente, y después todo debe ser desinfectado. El cloro debe ser diluido con agua corriente en proporción de cinco por ciento de cloro. Después deben ser lavados y desinfectados los utensilios para grillos (Erens et al., 2012).

Alimentación. El grillo doméstico es una especie omnívora por naturaleza, pero en cautiverio no se considera necesario darle alimento de origen animal. El alimento no debe faltar dentro de la jaula, de lo contrario puede comenzar el canibalismo entre éstos (Erens et al., 2012).

Aquí se explican dos formas en las cuáles el agua para grillos puede ser puesta dentro de la jaula (Porter, 2015): (1) Agua en forma líquida: el agua en forma líquida más recomendable para la crianza de grillo es: el agua purificada. El agua para grillos en forma líquida debe ser puesta en bebederos; (2) Agua en forma de frutas frescas, y vegetales frescos: los grillos pueden tomar, permanentemente y alternativamente, agua en forma de frutas frescas y vegetales frescos. Puede usarse como agua para grillos una gran variedad de frutas frescas y vegetales frescos, los cuáles sean ricos en agua como son: manzana, pera, melón, sandía, naranja, mandarina, papa, lechuga, rábano, col, etc. Todas las frutas y vegetales deben ser lavados y desinfectados antes de ser puestas en el bebedero para grillos. Pueden ser usadas simultáneamente estas dos formas de agua dentro de la misma jaula.

Los alimentos comerciales secos para nutrir animales domésticos, como son las aves y los mamíferos, pueden ser usados para nutrir grillos, las presentaciones más adecuadas para nutrir grillos son las que se venden en forma de croquetas o comprimidos para nutrir: roedores, conejos, pollos, cerdos, perros, gatos, etc. Estos alimentos no deben contener: medicamentos, hormonas, etc. Todos los alimentos sólidos deben ser finamente rayados, y / o molidos, y / o pulverizados antes de dárselos a los grillos.

Control y monitoreo. El criador debe tener fichas de control donde se toman notas diarias sobre el estado de cada jaula para grillos y de cada nido para grillos en uso, y sobre todas las actividades dentro de la locación. Se debe monitorear diariamente la temperatura, humedad y horas de luz. Los únicos grillos aceptables para ser usados dentro de la crianza, son los grillos nacidos en cautiverio obtenidos de una granja comercial de grillos libres de enfermedades (Weissman et al., 2012). 


\section{Nidos para grillos}

Un nido para grillos está formado por: (1) Substrato para guardar los huevos fertilizados de los grillos; (2) Bandeja contenedora del substrato, (3) Malla metálica protectora del substrato. Tapa protectora del substrato. Todos y cada uno de los nidos para grillos deben ser marcados en igual forma que con las jaulas para grillos (Fig. 3).

Los materiales más usados por los criadores de grillos como un substrato para guardar los huevos fertilizados de grillos son: vermiculita; arena marina o arena de río; tierra esterilizada comercial para plantas ornamentales, y piedra porosa volcánica. Se puede hacer una mezcla con dos o más de los cuatro materiales aquí nombrados, para asegurarse que el substrato pueda cubrir todos los requerimientos. La capacidad recomendada en la bandeja para ser usada como contenedora del substrato del nido para grillos es: desde ocho onzas, hasta veinticinco onzas de capacidad. El sustrato debe tener un mínimo de tres $\mathrm{cm}$ de profundidad, o un máximo de cinco $\mathrm{cm}$ de profundidad.

La malla metálica protectora del substrato del nido para grillos es usada en la fase de recepción de los huevos fertilizados de grillos, es decir cuando las hembras entierran sus propios huevos fertilizados en el substrato. La malla metálica protectora del substrato del nido para grillos sirve para evitar que los grillos adultos reproductores se coman los huevos fertilizados, y que los grillos adultos reproductores escarben en el substrato (principalmente los machos hacen esto), el cual puede terminar derramado por todo el fondo de la jaula. El mejor tipo de malla es una metálica galvanizada con aberturas cuadradas de dos mm por lado.

La tapa protectora del sustrato del nido para grillos está formada por la tapa de plástico original de la bandeja contenedora. El mejor tipo de malla metálica para este propósito es la malla metálica de aluminio, con aberturas que tengan: el tamaño más pequeño en graduación "micro malla de aluminio" usada en la electrónica.

Para la fase de incubación de los huevos fertilizados de grillo se debe quitar la malla metálica protectora del substrato. En seguida la tapa protectora del substrato se coloca sobre la bandeja, y es cerrada con el sellado. El nido para grillos está listo para ser colocado dentro de la incubadora para los huevos fertilizados de grillo.

\section{Crianza del grillo ( $A$. domesticus) como fuente alternativa de proteínas para el consumo humano}

La Tabla 1 muestra un cuadro comparativo según cinco referencias bibliográficas en relación al uso, valor proteico y ventajas del consumo de Orthoptera.

La cría de insectos como mini-ganadería ofrece grandes oportunidades para aumentar la oferta sin poner en peligro las poblaciones de insectos silvestres (Halloran \& Vantomme, 2013). Algunos consideran a los insectos como alimento que solo se deben consumir en períodos de hambre. Sin embargo, en la mayoría de casos en los que forman parte de la dieta local básica, los insectos se consumen debido a su sabor y no porque no haya 
TABLA 1. CUADRO COMPARATIVO EN RELACIÓN AL USO, VALOR PROTEICO, VENTAJASY DESVENTAJAS DE LA CRIANZA Y CONSUMO DE ORTHOPTERA

\begin{tabular}{|c|c|c|c|c|c|}
\hline Autor & $\begin{array}{c}\text { Ramos-Elorduy } \\
\text { et al. (2012) }\end{array}$ & $\begin{array}{l}\text { Pocco } \\
(2010)\end{array}$ & $\begin{array}{l}\text { Arango } \\
(2005)\end{array}$ & $\begin{array}{l}\text { Lizhang et al. } \\
\text { (2008) }\end{array}$ & Montealegre (1997) \\
\hline Uso & $\begin{array}{l}\text { Consumo } \\
\text { humano }\end{array}$ & $\begin{array}{l}\text { Alimento } \\
\text { (presas) de } \\
\text { animales } \\
\text { silvestres. }\end{array}$ & $\begin{array}{l}\text { Consumo } \\
\text { humano }\end{array}$ & Consumo humano & $\begin{array}{c}\text { Alimento de } \\
\text { animales (monos, } \\
\text { roedores, } \\
\text { murciélagos, aves, } \\
\text { lagartos, anfibios, } \\
\text { etc.) }\end{array}$ \\
\hline $\begin{array}{l}\text { Valor } \\
\text { Proteico }\end{array}$ & $\begin{array}{c}\text { De } 62 \text { a } 75 \% \text { de } \\
\text { proteínas }\end{array}$ & $\begin{array}{c}\text { Fuente primaria } \\
\text { de proteínas. }\end{array}$ & $\begin{array}{c}60 \text { a } 70 \% \text { de } \\
\text { proteínas }\end{array}$ & $\begin{array}{c}65 \text { a } 96 \% \text { de } \\
\text { proteínas }\end{array}$ & $\begin{array}{c}\text { Fuente primaria de } \\
\text { proteínas }\end{array}$ \\
\hline Ventajas & $\begin{array}{c}\text { Fácil } \\
\text { digestibilidad } \\
\text { Abundancia } \\
\text { del recurso. }\end{array}$ & $\begin{array}{c}\text { Fácil } \\
\text { disponibilidad }\end{array}$ & & $\begin{array}{c}\text { Elevada tasa } \\
\text { reproductora. } \\
\text { Corto ciclo biológico. } \\
\text { Digestibilidad de } \\
77,9 \% \text { a } 98,9 \% \text {. }\end{array}$ & No especifica \\
\hline
\end{tabular}

otras fuentes de alimentos disponibles, por lo que pueden alcanzar precios elevados y se consideran un manjar exquisito, y exótico (Belluco et al., 2013; Halloran \& Vantomme, 2013; Chakravorty et al., 2014).

No se conocen casos de transmisión de enfermedades o parásitos importantes a humanos derivados del consumo de insectos. No obstante, pueden producirse alergias comparables a las ocasionadas por los crustáceos, que también son invertebrados. En comparación con los mamíferos y las aves, los insectos pueden plantear un riesgo menor de transmisión de infecciones zoonóticas a los humanos, aunque este tema debe investigarse más a fondo (Halloran \& Vantomme, 2013). Lamentablemente, los insectos no son consumidos debido a restricciones y tabúes alimentarios (Dufour, 1987; Chakravorty et al., 2014).

La toxicidad de los insectos ingeridos por el hombre los clasifica en dos grupos: fanerotóxicos y criptotóxicos. Los primeros comprenden aquéllos que son ponzoñosos, 0 sea, que presentan un aparato de ponzoña que incluye: una glándula, un reservorio, un ducto y un aparato para inyectar la ponzoña. Pertenecen a este grupo algunos insectos de los órdenes Lepidóptera, Himenóptera y Hemíptera, cuyas secreciones son distribuidas tanto por aguijones retráctiles como por piezas bucales penetrantes o saetas urticantes. Las toxinas producidas por las especies fanerotóxicas son activas cuando son inyectadas, volviéndose inactivas en el tracto gastrointestinal. Sin embargo, se recomienda al individuo entomófago un mínimo de cuidado al ingerir insectos de esa categoría (Blum, 1994; Neto \& Ramos-Elorduy, 2006).

En cuanto a uso del suelo, los insectos son claramente mucho más pequeños, y pueden ser criados en mayores densidades. Esto permite aprovechar el espacio también en vertical, por lo que se pueden producir $64 \mathrm{~kg}$ de insectos por m cúbico, frente a los 40 $\mathrm{kg}$ por m cuadrado de carne de pollo o los 0,13 kg por m cuadrado de carne de vacuno (Echávarri, 2013; Dzamba, 2014). 
A su vez, los insectos pueden ser alimentados con partes vegetales desechadas de la dieta humana, como tallos y hojas, o plantas naturales no aprovechadas por el hombre (Defoliart, 1995; Chakravorty et al., 2014). Los insectos son mucho más eficaces a la hora de convertir la comida en masa corporal ya que al ser la mayoría de ellos poiquilotermos, no gastan parte de la energía que ingieren en mantener su calor corporal, como aves y mamíferos. Los insectos son cinco veces más eficientes que el ganado vacuno en la conversión de energía, y si consideramos que el porcentaje de materia comestible del total del animal es más alto en los insectos que en el ganado ( $80 \%$ frente al $40 \%$ del de vacuno), la eficacia asciende a 12 veces (Quirce et al., 2013; Chakravorty et al., 2014).

La información del presente trabajo cumple con brindar alcances bibliográficos de la crianza del grillo (A. domesticus) como fuente alternativa de proteínas para el consumo humano (Halloran et al., 2014). Los estudios coinciden en que los grillos contienen más proteínas, y por lo tanto, son una alternativa saludable y nutritiva, además de sostenible en comparación a las opciones tradicionales, como pollo, cerdo, carne de vaca e incluso pescado (Echávarri, 2013; Ramos-Elorduy \& Pino, 2001)).

\section{Referencias bibliográficas}

ARANGO, G. 2005. Los insectos: una materia prima alimenticia promisoria contra la hambruna. Revista Lasallista de Investigación, 2: 33-37.

Arango, G.G.P.; Vergara-Ruiz, R.A. \& MejíA-VéleZ, H. 2004, Análisis composicional, microbiológico y digestibilidad de la proteína de la harina de larvas de Hermetia illuscens (Diptera: Stratiomyiidae) en Angelópolis-Antioquia, Medellín, Colombia. Revista Facultad Nacional de Agronomía, 57: 2491-2499.

Belluco, S.; Losasso, C.; Maggioletti, M.; AlonzI, C.C.; PAoletti, M.G. \& RicCl, A. 2013. Edible insects in a food safety and nutritional perspective: A critical Review. Comprehensive Reviews in Food Science and Food Safety, 12: 296-313.

BIDAU, C.J. 2014. Patterns in Orthoptera biodiversity. II. The cultural dimension. Journal of Insect Biodiversity, 2: 1-15.

BLUM, M. 1994. The limits of entomophagy: a discretionary gourmand in a world of toxic insects. The Food Insects Newsletter, 7: 6-11.

Caparros-Megido, R.; Sablon, L.; Geuens, M.; Brostaux, Y.;Alabi, T.; BleCKer, C.; Drugmand, D.; Haubruge, E. \& FRANCIS, F. 2014. Edible insects acceptance by Belgian consumers: promising attitude for entomophagy development. Journal of Sensory Studies, 29: 14-20.

ChAKRAVORTY, J.; GHOSH, S.; JUNG, C. \& MEYER-ROCHOW, V.B. 2014. Nutritional composition of Chondacris rosea and Brachytrupes orientalis: Two common insects used as food by tribes of Arunachal Pradesh, India. Journal of Asia-Pacific Entomology, 17: 407-415.

Defoliart, G. 1995. Edible insects as minilivestock. The Food Insects Newsletter, 8: 8-10. 
DPS (Distrends Planeta Sustentable). 2014. La Industria de insectos comestibles está en crecimiento. (Recuperado 2015). Disponible en: https://distrends.com/la-industria-de-insectos-comestibles-esta-en-crecimiento/

DUFOUR, D. 1987. Insects as food: a case study from the Northwest Amazon. American Anthropologist, 89: 383-397.

DZAMBA, J. 2014. Third Millennium Farming: utilizing city bio-wastes in a strategy for high-yield urban farming. Abstract book Conference "Insects to Feed The World" - The Netherlands 14-17 May 2014. FAO. p. 127.

ECHÁVARRI, V. 2013. Bovinos-carne-producción-comercio. Oficina de estudios y políticas Agrarias - Ministerio de Agricultura de Chile (Recuperado 2014) disponible en www.odepa.cl/ odepaweb/publicaciones/doc/11102.pdf

ERENS, J.; Es VAN, S.; HAVERKORT, F.; KAPSOMENOU, E. \& LUIJBEN, A. 2012. A bug's life large-scale insect rearing in relation to animal welfare. Wageningen University. Project commissioner VENIK. 57 p.

EsCOBAR, A. 2013. Granja casera para criar y comer insectos. Última actualización: 29-072013 (recuperado 2014) disponible en: http://www.swagger.mx/tecnologia/ granja-casera-para-criar-y-comer-insectos.

FAO (Food and Agriculture Organization of the United Nations). 2014. Aprovechar el potencial de los insectos para la alimentación animal. (Recuperado en 2014) disponible en: http://www. fao.org/news/story/es/item/231855/icode/

FIA (Fundación para la Innovación Agraria). 2013. En base a harina de insectos desarrollan alimento para salmones y truchas. Fundación para la Innovación Agraria, FIA, (Recuperado 2015) disponible en: http://www.infocyt.cl/articulo.php?id=288.

Ganguly, A.; Chakravorty, R.; Das, M.; Gupta, M.; Mandal, D.K.; HaldaR, P.; Ramos-ElorduY, J. \& PinoMORENO, J.M. 2013. A preliminary study on the estimation of nutrients and anti-nutrients in Oedaleus abruptus (Thunberg) (Orthoptera: Acrididae). International Journal of Nutrition and Metabolism, 5: 50-65.

GariBaY, R. 2007. Zootecnia del grillo. Tesis. Universidad Michoacana de San Nicolás de Hidalgo, Facultad de medicina veterinaria y zootecnia, Morelia.

GOHAR, L. 2012. Can good design make eating bugs more palatable (Recuperado 2015). Disponible en: http://www.foodrepublic.com/2012/04/13/can-good-design-make-eating-bugsmore-palatable

HALloRAn, A. \& VANTOMme, P. 2013. Guía informativa, basada en el documento "Edible insects: future prospects for food and feed security" (Recuperado 2014). Disponible en: www.fao.org

Halloran, A.; MUenKe, C.; Vantomme, P. \& Van Huis, A. 2014. Insects in the human food chain: global status and opportunities. Food Chain, 4: 103-118.

HIDALGO, J. 2005. Insectos como alimento. Publicación en Eroski Consumer. (Recuperado 2014). Disponible en: www.consumer.es

LIZHANG, W.; MONTESINOS, J.L.V. \& DINGHONG, Y. 2008, Los insectos como fuente de alimento: Análisis del contenido en proteína y grasa de 100 especies. Boletim do Museu Municipal do Funchal (Historia Natural), Sup. 14: 55-70. 
Mazurkiewicz, A.; Tumialis, D.; PeZowicz, E.; JurbańSkI, J.; Galewskı, P. \& Góral, K. 2013. The effect of density on the breeding optimization of the tropical house cricket Gryllodes sigillatus (Walker) (Orthoptera: Gryllidae). Annals of Warsaw University of Life Sciences - SGGW Animal Science, 52: 135-139.

MELLADO, S. 2013. Una ración de grillos, saltamontes y larvas. (Recuperado 2015). Disponible en: http:// ccaa.elpais.com/ccaa/2013/06/27/andalucia/1372365177_507082.html

MONTEALEGRE, F. 1997. Estudio de la fauna de tettigoniidae (Orthoptera: Ensifera) del valle del Cauca. Universidad Del Valle, Cali. (Tesis de Biólogo). $266 \mathrm{p}$.

NAKAGAKI, B.J. \& DEFOLIART, G.N. 1991. Comparison of diets for mass-rearing Acheta domesticus (Orthoptera: Gryllidae) as a novelty food and comparison of food Conversion efficiency with values reported for livestock. Journal of Economic Entomology, 84: 891-896.

NATURA. 2013. Los diez insectos más comestibles. (Recuperado 2014). disponible en: http://www.abc. es/natural-biodiversidad/20130515/abci-dieta-insectos-comestibles-201305141140.html

NAvarRo, J. 2013, Cría de grillos. (Recuperado 2014). disponible en http://www. reptilium.galeon. com/cria_grillos.html

Neto, E.M.C. \& RAmOS-EloRduy, J. 2006. Los insectos comestibles de Brasil: etnicidad, diversidad e Importancia en la alimentación. Boletín Sociedad Entomológica Aragonesa, 38: 423-442.

OKore, O.; AvaOja, D. \& NwANA, I. 2014. Edible Insects of the Niger Delta Area in Nigeria. Journal of Natural Sciences Research, 4: 1-9.

Parajulee, M.G.; Defoliart, G.R. \& HogG, D.B. 1993. Model for use in mass-production of Acheta domesticus (Orthoptera: Gryllidae) as food. Journal of Economic Entomology, 86: 1424-1428.

PÉREZ, D. \& IANNACONE, J. 2006. Aspectos de la bioecología de Rhynchophorus palmarum (Linnaeus) (Coleoptera: Curculionidae) en el pijuayo (Bactris gasipaes H.B.K.) (Arecaceae), en la Amazonía peruana. Revista peruana de entomología, 45: 138-140.

PÉREZ, D.; IANNACONE, J. \& PINEDO, H. 2010. Toxicological effect from the stem cortex of the amazonic plant soapberry Paullinia clavigera (Sapindaceae) upon three arthropods. Ciencia e Investigación Agraria, 37:133-143.

PIJOAN, M. 2001. El consumo de insectos, entre la necesidad y el placer gastronómico. Offarm: Farmacia y Sociedad, 20:150-161.

Pocco, M. 2010. Comunidades de ortópteros (Insecta, Orthoptera) en pastizales del Chaco Oriental Húmedo, Argentina. Animal Biodiversity and Conservation, 33.2: 119-129.

PORTER, R. 2015. Caring for feeder Crickets. General Manager of the Australian Reptile Park in NSW. (Recuperado 2015). Disponible en: http://www.reptilepark.com.au/

Quintero, B.; Ramos, B.; Ramos-Elorduy, J.; PInO, J.; Ángeles, S.; García, A. \& BARRera, D. 2012. Análisis químico y nutricional de tres insectos comestibles de interés comercial en la zona Arqueológica del Municipio de San Juan Teotihuacán y en Otumba, en el Estado de México. Interciencia, 37: 914-920.

QUIRCE, C.; FILIPPINI, V. \& MICÓ, E. 2013. La utilización de los insectos en la gastronomía, un taller nutritivo, Cuadernos de biodiversidad, 43: 11-21. 
RAmOS-ELORDUY, J. \& PINO, M.J.M. 2001. Contenido de vitaminas de algunos insectos comestibles de México. Journal of the Mexican Chemical Society, 45:66-76.

RAmOs-ElorduY, J. \& VIEJO, M.J. 2007. Los insectos como alimento humano: Breve ensayo sobre la entomofagia, con especial referencia a México. Boletín de la Real Sociedad Española de Historia Natural, 102: 61-84.

Ramos-Elorduy B.J.; PIno-Moreno, J.M. \& Martínez-CamaCho, V.H. 2012. Could Grasshoppers be a nutritive meal? Food and Nutrition Sciences, 3: 164-175.

RAUBENHEIMER, D. \& ROTHMAN, J.M. 2013. Nutritional ecology of entomophagy in humans and other primates. The Annual Review of Entomology, 58:141-160.

RYDER, J.J. \& SIVA-JOTHY, M.T. 2001. Quantitative genetics of immune function and body size in the house cricket, Acheta domesticus. Journal of Evolution Biology, 14: 646-653.

SANCHO, D.; ALvAREZ, G.M.J.\& FERNÁNDEZ, S.L.R. 2015. Insectos y alimentación. Larvas de Rhynchophorus palmarum $\mathrm{L}$, un alimento de los pobladores de la Amazonía Ecuatoriana. Entomotropica, 30: $135-149$.

Steinfeld, H.; Gerber, P.; WassenaAr, T.; CASTel, V.; Rosales, M. \& de HaAn, C. 2006. Livestock's long shadow. FAO, Roma: 390p.

Weissman, D.B.; Gray, D.A.; Pham, H.T. \& TIJSSEN, J. 2012. Billions and billions sold: Pet-feeder crickets (Orthoptera: Gryllidae), commercial cricket farms, an epizootic densovirus, and government regulations make for a potential disaster. Zootaxa, 3504: 67-88. 
